\title{
A Novel Method to Produce Kiss-bonds in Composites Components for NDI and
}

\section{Characterisation Purposes}

\author{
R. Telford ${ }^{1}$, A. O'Carroll' ${ }^{1}$, R. S. Pierce ${ }^{2,3}$, T. M. Young ${ }^{1 *}$ \\ ${ }^{1}$ Irish Composites Centre (IComp), School of Engineering, Bernal Institute, University of Limerick, Ireland \\ ${ }^{2}$ Department of Mechanical, Materials and Manufacturing Engineering, University of Nottingham Ningbo China, P.R. \\ China \\ ${ }^{3}$ School of Mechanical and Aerospace Engineering, Queen's University Belfast, United Kingdom
}

\begin{abstract}
Kiss-bonds (kissing bonds) are a defect type that feature a localised loss of structural continuity within the material, yet the material remains in intimate contact across the defect. Typically, shear and normal tensile stresses cannot be conducted across such defects (although, pure compressive stresses are possible). Kiss-bond defects are difficult to detect reliably both within the bulk of the material (interlaminar) and within bond-lines of adhesively bonded joints or repairs - using conventional Non-Destructive Inspection (NDI) techniques. Compounding this issue is the lack of a reliable technique to create representative kiss-bond defects in a controlled fashion for the purpose of NDI equipment calibration or development, or scientific investigation.

A novel method for manufacturing composite material test panels with kiss-bond defects (for research or NDI calibration, for example) in a controlled and repeatable fashion has been developed. Small areas of two adjacent pre-preg plies were pre-cured before being incorporated within a laminate. During consolidation, no bonding occurs between the pre-cured areas, thus creating a kiss-bond defect of known geometry. Test panels with $6 \times 6 \mathrm{~mm}$ and 10x10 mm kiss-bond defects were manufactured. The robustness of the technique was verified using ultrasonic and laser shearography NDI methods; 7 of the 10 manufactured defects were classified as kiss-bonds, with the remaining 3 identified as dis-bonds.
\end{abstract}

Keywords: Kiss-bonds, weak bonds, Non-Destructive Inspection (NDI)

\section{Introduction}

\subsection{Background}

Advanced composite materials, such as Carbon Fibre Reinforced Plastic (CFRP), possess excellent strength-to-weight and stiffness-to-weight ratios, which in many cases are superior to metals [1,2]. These properties are driving an increased demand for composite materials for many automotive, wind energy and aerospace applications [3]. In particular, modern passenger jets - including the Boeing 787, Airbus A350 and A220 (Bombardier C-Series) aircraft types - all rely on advanced composites (CFRP) for load-bearing primary structures, such as wing boxes, wing and fuselage skins, and stringers $[1,2,4]$.

As the well-established procedures employed to inspect the previous generation of metallic structures do not usually transfer to composite structures, new techniques for defect detection are required. Damage in metallic structures will generally result in dents or cracks, which can be easily detected by visual inspection. Composite materials, on the other hand, are prone to internal damage which is not always visually evident on the surface. Such damage degrades structural integrity, and thus Non-Destructive Inspection (NDI) techniques are required to 'see into' the material and detect hidden sub-surface damage in a non-invasive manner $[1,2,5]$. This is required at a manufacturing stage (quality control), during 
service (damage assessment), and during bonded repairs (e.g. to assess the quality of the repair) [1, 4-6]. Effective NDI techniques, along with an understanding of the degraded performance caused by defects, are therefore a necessity for critical structural components.

Examination of the literature indicates a lack of a clear and universally accepted definition of kiss-bonds, which compounds the issue of performing an effective evaluation of NDI detection techniques. Based on input from several reputable industrial sources, and existing research in this field [19, 21, 22, 23, 25], the following definition for a kiss-bond was adopted for the work herein described: kiss-bonds (kissing bond) are defects where there is a loss of structural continuity within the material, yet all surfaces remain in intimate contact with no cavity being formed. A kiss-bond can thus be described as having no bonding across the plane of the defect; this defect type can be contrasted to a dis-bond, where an easily-detectable internal cavity is formed, as well as a weak-bond, in which poor bonding across the plane of the defect exists [19, 21, 22, 23, 24].

Various research groups have approached this topic and have attempted to define and interrogate kissing bonds, resulting in inconsistencies in the definition of a kiss-bond [7]. For instance, Brotherhood et al [23] suggested that kissing bonds should be broken down into "wet" and "dry" kiss-bonds depending on the mechanism that produces the defects. Marty et al [12] stated that the lap shear strength was required to be below $20 \%$ of the nominal adhesive performance and exhibit purely adhesive failure. Furthermore, certain authors, including Jeenjitkaew and Guild [26], also consider defects where surfaces are in intimate contact but still have some bonding across the plane of the defect, as kiss-bonds - such defects are instead distinguished as weak-bonds for this research.

The stress transfer capabilities of the material (e.g. through interlaminar shear) are severely compromised when kiss-bonds are present. Consequently, the continued safe utilisation of a component relies on either (1) an overly-conservative design approach, whereby the structure is sufficiently over-designed to accommodate kiss-bonds, or (2) clearly defined NDI capabilities to both detect and assess the defect $[1,10]$. As the latter option allows for a reduction in material use and further weight savings, it is advantageous to develop NDI technologies to address these needs. The nature of a kiss-bond, however, severely hampers this approach. Firstly, the defect is sub-surface, and so no evidence of its existence is visible on the surface of the component. Secondly, as the surfaces of the defect are in contact, there is little in the way of a change in physical property for NDI systems to detect [4, 9]. Lastly, the defect type can occur at any depth within monolithic, sandwich, bonded joints and repaired parts, all of which may each require a different NDI approach.

Certain NDI techniques are described - in the open literature - as being able to detect and assess kiss-bonds. However, the precise abilities and limitations of these techniques are largely unknown [1, 4, 5, 7, 9, 11]. Crucially, this is recognised by the Federal Aviation Authority (FAA), which states that the inspection of weak-bonds (and by extension, kiss-bonds) in composites "is open for future advancement and validation of non-destructive inspection (NDI) technology to detect weakbonds, which degrade over time and lead to adhesion failures. Such technology has not been reliably demonstrated at a production scale to date" [10]. Therefore, it can be argued that further exploitation of composites in safety-critical industrial sectors, such as aerospace, relies on two critical factors:

1. Determination and characterisation of the effect of defects on the structure's load-carrying capability;

2. Evaluation of available NDI technologies to determine their limits with regards to damage detection and assessment capabilities. 
To realise these two points, a representative, controllable and repeatable kiss-bond manufacturing process is required. Such an approach allows for rigorous evaluation of various NDI systems, as well as mechanical assessment of these defects. Combining the output of an NDI system with the results of mechanical testing could significantly advance damage assessment of composite structures, as the residual strength of the structure can be inferred from an NDI scan.

\subsection{Current Approaches}

Several popular NDI techniques exist to detect and assess defects in composite materials, including ultrasonics $[4,5,8,12-$ $16,21]$, laser shearography $[4,12,17,21]$, thermography $[4,12,15,16,21]$, laser bond inspection [11, 16], Vibro-Acoustic Modulation (VAM) [13] and x-ray [4]. Other notable, but less popular, methods include lamb wave [18], Digital Image Correlation (DIC) [14], second-harmonics [16, 19], percussion diagnostics [5], microwave [15, 21] and vibrational methods [20]. The abilities of these techniques at detecting certain defect types, such as moisture ingress or de-bonding, are generally well known. This is not the case for kiss-bond defects, which remain challenging to detect. Table 1 describes the operating principles of six popular NDI techniques. Each system relies on a different defect characteristic for the purpose of damage detection. A representative kiss-bond defect must therefore offer physical characteristics of a kiss-bond only, and not additional characteristics that might be detectable by an NDI system.

The current approaches of using film insertions, [4, 13, 27] "pillow" insertions [4, 15, 21], contaminants [4, 8, 9, 12, 15, $16,21,28]$, uncured resin [13], pull tabs [4, 9] or electrically de-bonding adhesives [12] have several limitations in accurately simulating kiss-bonds, and can lead to misleading results. For example, Chen et al. [13] used film insertions and uncured resin to simulate delamination and kiss-bonds. The film insertions were detectable using ultrasonics and VAM, whereas the uncured resin were only detectable using VAM. This demonstrates the difficulty in drawing conclusions from one NDI systems' ability to detect kiss-bonds.

Film insertions simulate a kiss-bond by creating a structural discontinuity. However, insertions are a defect type themselves, and thus introduce additional physical characteristics for an NDI system to detect, leading to ambiguous results $[9,13,17]$. Ultrasonics may detect the additional interface at the insertion surfaces, while thermography will detect the change in thermal conductivity caused by the film insertion, and not the simulated kiss-bond. These issues are further compounded when "pillow" insertions are used. A pillow insertion is created by sealing a small package of film material, with air trapped inside $[4,15,21]$. In this case, a dis-bond is essentially created in place of a kiss-bond.

Contaminants are often a source of kiss-bonds, and so they can appear as an obvious choice to reproduce the defect. However, using contaminants also leads to undesirable consequences $[8,12,16]$. Contaminants work by locally reducing or eliminating the bonding between two plies. Several different contaminants have been used by various authors, including, but not limited to: release agents [4, 8, 9, 15, 16], PTFE [9, 15], water [16], silicone-based oil [9, 12, 16], grease [4, 16], baking powder [9, 16], wax [9, 16] and sand [9, 16]. In a study undertaken by Marty et al. [12] it was noted that most contaminants do not strongly influence the bonding strength, provided that they do not contain silicone. In addition, it is difficult to control the size and shape of the defect (e.g. due to smearing of the contaminant when cure pressures are applied). The requirements of zero-bonding and known defect size are therefore challenging to meet in a reliable and repeatable fashion. Furthermore, as additional material is introduced, the existence of the contaminant may be detected by the NDI system, as opposed to the simulated kiss-bond. 
Chen et al. [13] used a technique similar to contaminants to represent a kiss-bond. In this case, epoxy resin, without hardener, was poured into a thin crack to simulate a poor adhesive repair. The uncured resin fills the volume of the thin crack, resulting in no discontinuity in the material (hence, intimate contact), yet no stress transfer can be conducted across the bond-line. As with contaminants, however, the new material interface may be detectable by NDI systems, as opposed to the existence of a kiss-bond.

Pull-tabs have also been utilised, whereby the material is cured with an insertion (tab) protruding beyond the extremities of the component [4]. Once the component is fully cured the tab can then be removed, resulting in a discontinuity in the material. However, a small gap (with the thickness of the removed film) is formed across the defect width, meaning the surfaces are not in intimate contact as required for a kiss-bond. In addition, this technique produces a defect that runs to a free edge, therefore limiting its potential for NDI system assessment and residual strength characterisation.

The technique developed in the current work aims to address the above-mentioned issues by directly creating kiss-bonds in composite structures, controlling the defect size, shape and location. Manufactured components (or test panels) incorporating kiss-bond defects can then be used in a meaningful assessment of the capabilities of alternative NDI systems and also to assess the impact of the defects on the structural integrity of components under in-service conditions. This technique can be applied to all construction techniques that use a thermosetting curing process (e.g. for monolithic and sandwich constructions, with woven and unidirectional materials) or bonding process for manufacturing subassemblies or conducting repairs.

\subsection{Objectives}

The following objectives were established for this research investigation:

1. Develop a method to directly create kiss-bond defects in monolithic CFRP composite panels, in a repeatable manner, accurately controlling both the size and location of the defects in the pre-preg material;

2. Detect and assess the manufactured defects using ultrasonics and laser shearography NDI techniques, and determine the nature of the defect created (i.e. kiss-bond or dis-bond); and

3. Inspect the manufactured defects through destructive inspection (microscopy).

The layout of this paper is as follows. The technique developed for the preparation of kiss-bond defects, in terms of the apparatus and method verification, is described in Section 2. The panels produced for NDI evaluation are also described in this section. The NDI detection and assessment is then detailed in Section 3, followed by an assessment using various microscopy techniques in Section 4. In Section 5, the technique developed is discussed further in terms of strengths, weaknesses and opportunities for further development.

\section{Kiss-bond manufacturing method}

\subsection{Introduction}

The method involves initially curing a discrete area of a thermoset pre-preg ply to the size and shape of the desired defect. The process is repeated for a second ply, which is then placed on top of the first ply, so that the two pre-cured areas are in contact. Subsequently, additional uncured plies are added in the usual fashion to create a laminate, which is then autoclave cured. Due to the thermosetting nature of the resin, no additional resin flow/cross-linking occurs across the pre-cured areas during the subsequent cure cycle. This results in zero inter-lamina bonding in that area, thus creating a kiss-bond defect of known geometry. 
Three aspects of the manufacturing process were identified as being critical to producing repeatable kiss-bonds: (1) the surface finish must be smooth and flat to maintain intimate contact across the pre-cured areas. (2) The pre-cured areas must undergo a complete cure prior to the laminate cure cycle, otherwise, bonding could occur across the defect. (3) The edges of the pre-cured areas need to be well defined, so that there is a clear boundary to the area of the manufactured defect (i.e. not a gradual transition from uncured to cured material).

\subsection{Materials, apparatus and methods}

The material chosen for this study was Hexcel 8552, a Carbon Fibre Reinforced Plastic (CFRP) pre-preg material. The material consists of biaxial carbon fibres pre-impregnated in a thermosetting epoxy matrix (cure temperature of $179^{\circ} \mathrm{C}$ ). The irreversible cure property of the matrix was exploited in this application to ensure that no further curing - and thus bonding - occurred between the pre-cured areas during the laminate cure cycle. All laminates were manufactured from 8 pre-preg plies, with areas of the two mid-plies pre-cured to create kiss-bonds.

The pre-curing of the material was performed using an electrically powered heating element attached to an aluminium block. The block features the desired defect shape extruded from the bottom surface. The heating element is mounted on the top surface of the block, transferring heat into the block through conduction. This heats the extruded defect shape, which is then placed in contact with the CFRP material (see Figure 1 for an exploded view of the apparatus).

The heat applied must be precisely controlled to ensure that the defect area undergoes complete cure while the surrounding area remains uncured. This requires that the heat remains localised and does not flow to the surrounding material. Control of the heat is accomplished by partitioning the tool-plate so that the area directly under the material being cured is separated from the surrounding tool-plate by an air gap. Differential Scanning Calorimetry (DSC) analysis of material surrounding pre-cured areas confirmed that this area was unaffected by the pre-cure cycle. This is shown by the insulation block in Figure 1.

Two plies are involved in the creation of a kiss-bond. The location of the pre-cured areas on these two plies must be identical to ensure that they align correctly when the two plies are stacked. To facilitate this, the tool-plate is marked to ensure that the plies can be located identically during the pre-cure process. In addition, a mount is used for the electrical heater/stamp assembly. The mount attaches to the tool-plate, locking its position in relation to the insulation block, which defines the defect area.

In order to provide a flat and smooth surface finish, the ply being prepared is placed under a vacuum bag, with release film being used to keep the ply clean and to keep it from bonding to the tool-plate.

\subsection{Processing parameters}

The processing parameters of the kiss-bond manufacturing technique are temperature, ramp rate and cure time. These parameters were defined to ensure that they can reliably pre-cure the kiss-bond area. A thermocouple was used to monitor the temperature and control the output of the heating element. Obtaining a temperature reading at the ply is not possible, as introducing a thermocouple at this location would leave an imprint on the ply's surface. Therefore, the thermocouple was mounted at the electrical heating element (as indicated in Figure 1). It is worth noting that the temperature reading at this location does not provide the material (and thus the curing) temperature. Rather, it is a processing temperature that results in a dwell time of a certain duration being required to guarantee a complete cure. A processing temperature (read from the thermocouple location in Figure 1) was fixed, and the dwell time altered until a Differential Scanning Calorimetry (DSC) analysis indicated that no further curing reactions were occurring. A Perkin-Elmer Pyris 1 system was used for this purpose. This provided a total dwell time for the material to reach a full cure. Logging temperature from eight different 
trials indicated that the system was capable of holding the dwell temperature within $+/-2.6^{\circ} \mathrm{C}$. In addition, at a selected ramp rate of $15{ }^{\circ} \mathrm{C} / \mathrm{min}$, the actual ramp rates recorded were within the range of $13-14.5^{\circ} \mathrm{C} / \mathrm{min}$ (measured over four separate trials).

The defined cure profile used a temperature ramp rate of $15^{\circ} \mathrm{C} / \mathrm{min}$, and a dwell time of 120 min at $195^{\circ} \mathrm{C}$. These values were chosen to be overly conservative, to ensure that the pre-cured areas do not undergo further curing in the autoclave.

\subsection{Panels produced}

Five panels were manufactured with kiss-bonds, to the dimensions shown in Figure 2, to verify the method. The defect sizes of $6 \times 6 \mathrm{~mm}$ and $10 \times 10 \mathrm{~mm}$ were chosen based on an industry recommendation (sizes were deemed relevant to aerospace applications). This small size is challenging to produce and detect, and yet is large enough not to be within damage tolerant design criteria. Following the lay-up process, the panels were autoclave cured as per the manufacturer defined curing cycle. No cutting or trimming took place following the cure to ensure that the defects were not agitated, potentially worsening the defect or creating a dis-bond.

\section{Non-destructive Inspection}

A visual assessment of the manufactured panels gave no indications of the existence of any sub-surface defects. No ridges, lips or other flaws could be seen or felt on the surface above the defect areas. The defects were analysed with both ultrasonics and laser shearography NDI systems. The two systems were evaluated in terms of their ability to detect the defects, and - in the case of ultrasonics - to determine whether a kiss-bond or a dis-bond had been created.

\subsection{Ultrasonics}

The defect areas were then examined via ultrasonics, using a GE Phasor XS system with a $5 \mathrm{MHz} 64$ probe phased-array roller. Water was used as a couplant. The equipment was calibrated by scanning an undamaged area of the panel and ensuring that the back-wall was accurately identified. A C-scan analysis of the panels led to all manufactured defects being readily detected and a combination of $\mathrm{A}$ - and $\mathrm{B}$-scans were used characterise the defects.

An example of results from ultrasonics testing is given in Figure 3, with the C-scan data on the left (showing both 'Amplitude' and 'Time-of-Flight' data) and A-/B- scan data on the right. The C-scan shows a plan-view of the defects, with the $10 \times 10 \mathrm{~mm}$ and $6 \times 6 \mathrm{~mm}$ squares being on the left and right of the image, respectively. The A-/B-scan images give a cross-sectional view of the defect, with the $10 \times 10 \mathrm{~mm}$ defect on the top and the $6 \times 6 \mathrm{~mm}$ defect on the bottom. The procedure for detecting and assessing the defects was as follows. A B-scan of the panel was taken by rolling the probe along the surface until an anomaly was evident indicating the existence of a defect. Subsequently, the defect was interrogated further by adjusting the interference, amplitude, and time-of-flight gates on the A-scan signal. The interference gate (identified in Figure 4) was adjusted to miss the interference caused by the roller-probe. The amplitude gate was set to be triggered by the defect, while avoiding the front and back-walls. Finally, the time-of-flight gate was adjusted so as to be triggered by anything after the front wall.

Using this set-up, the nature of the defect (i.e. kiss-bond or dis-bond) could be determined. By monitoring the back-wall echo from the area under the defect using a combination of the A- and B-scans. If the defect is detectable, it is - by definition - reflecting parts of the sound wave from reaching the back-wall, and thus a reduction in the return from the back-wall is expected. In the case of a dis-bond, a majority of the signal will be returned from the defect, resulting in a clear and significant break in the back-wall. In the case of a kiss-bond, the majority of the signal passes through the defect unabated. This results in a relatively weak return from the defect, while giving a strong and continuous return from the back-wall 
under the defect. Care must be taken at this stage to ensure that it is the back-wall itself - and not an echo of the defect that is being observed.

It can be seen in the ultrasonics return of panel 1 (Figure 3) that both defects were detectable by C-Scan. The A-/B-scan of the $10 \times 10 \mathrm{~mm}$ square shows that the defect breaks the back-wall completely, indicating that in this instance a dis-bond was created. On the other hand, the back-wall of the $6 \times 6 \mathrm{~mm}$ defect remains largely unchanged, and so it is determined that a kiss-bond was formed in this instance. This is shown further by the time-of-flight, which shows a clear break at the back-wall for the $10 \times 10 \mathrm{~mm}$ defect (dis-bond) and a less significant break for the $6 \times 6 \mathrm{~mm}$ defect (kiss-bond).

The A-/B-Scan of the $10 \times 10 \mathrm{~mm}$ defect of panel 2, as shown in Figure 4, shows a clear break in the back-wall, indicating a dis-bond was created. This is further confirmed by the clear return in the time-of-flight. The $6 \times 6$ mm defect initially was not detectable by C-Scan. Close examination of the A-/B-Scan, however, showed a faint return at the mid-plane, indicating that there is a defect present, and that the majority of the sound wave passed through. This indicates that a highquality kiss-bond was formed, with good surface contact across the area of the defect. This is also demonstrated by the time-of-flight, which shows an almost imperceptible return from this defect. Destructive testing and sectioning (detailed in Section 4) of similar defects does indeed show that there is no bonding across this defect area despite intimate contact.

The defects in panel 3 (Figure 5), also appear to be a dis-bond (10 x $10 \mathrm{~mm}$ defect) and a kiss-bond (6 x $6 \mathrm{~mm}$ defect). A clear break is shown in the back-wall (A- and B- scan) for the $10 \times 10 \mathrm{~mm}$ defect, and it is clearly observed in the time-offlight. The 6 x $6 \mathrm{~mm}$ defect is not as easily detected in the C-scan, and the back-wall remains largely intact in the A-and B-scan.

Two high quality kiss-bonds were detected in panel 4 (Figure 6). The Amplitude C-Scan returns from the defects were relatively weak, indicating that the majority of the signal passed through the defect. Likewise, the A- and B-scans shows the strength of the back-wall echo was largely unaffected by the defect. The time-of-flight also shows minimal blanking of the back-wall caused by the defect.

Finally, two kiss-bonds were detected in panel 5 (Figure 7). The returns from the defect were relatively weak. To the point where the 6 × $6 \mathrm{~mm}$ defect did not even trigger the Amplitude gate. The strength of the back-wall is reduced in the B-scan shown; however, time of flight showed very little change in the back-wall due to the defects.

A summary of the results of the ultrasonics investigation are shown in Figure 8. It was determined that seven of the ten defects were kiss-bonds, while the remaining three showed signs of dis-bonding. Four of the ten $10 \times 10 \mathrm{~mm}$ were deemed to be kiss-bonds, while all ten of the 6 x $6 \mathrm{~mm}$ defects were deemed to be kiss-bonds.

\subsection{Laser shearography}

Laser shearography was also used to detect and analyse the defects. A Defect Dtect system manufactured by Laser Optical Engineering Ltd. was used, as shown in Figure 9(a). This consists of an illumination module (DDIM-150), which contains a class $2 \mathrm{M}$ laser with a wavelength of $532 \mathrm{~nm}$ and an imaging module (DDSM-15), containing a CCD camera with image resolution of $1280 \times 1024$ pixels and a frame rate of $25 \mathrm{fps}$.

The specimen was rigidly clamped to right-angle support sections, which in turn were fastened to a 20 mm thick steel toolplate. Such a set-up reduces rigid-body-motion of the specimen, which allows for an increase in sensitivity of the shearography system (crucial for the low surface strains expected from kiss-bonds).

Thermal excitation was used, by placing an infrared lamp (120 W) behind the specimen for approximately 30 seconds (shown in Figure 9(b)). In order to improve in-plane and out-of-plane resolution, the camera was placed directly ahead of the specimen at a distance of approximately $1.5 \mathrm{~m}$, with the laser illuminating the specimen from a $45^{\circ}$ angle. The results were obtained using $5 \mathrm{~mm}$ of horizontal shear. Once the specimen was heated, the interference patterns were monitored 
until the defects appeared (typically after 3 minutes). The Defect Dtect software was used for all image capturing and processing.

Using this procedure, all the defects were detectable. Figure 10 shows images for two of the panels as extracted from the Defect Dtect (note: the images show approximately 110 x $110 \mathrm{~mm}$ of the panels). It must be noted that shearography involves actively monitoring the progression of an interference pattern on the surface of the specimen. As the interference pattern develops over the surface, any sub-surface defects appear as an anomaly in this pattern, which is more easily identified as the pattern moves along the surface. With the small defects used in this study, the defects were clearly observable during live scanning, but became more difficult to identify from the screenshots taken.

Although the defects were readily detectable, the defect characteristics (i.e. kiss-bond or dis-bond) were not clearly evident. While the technique may lend itself to further interrogation of the defect types, no such technique is known to the operators and thus shearography was not used to investigate the defect types any further.

\section{Destructive inspection via microscopy}

\subsection{Specimen preparation}

Two specimens were prepared from panel 2 for microscopy of the internal 6 x $6 \mathrm{~mm}$ and 10 x $10 \mathrm{~mm}$ defects. This panel was chosen as ultrasonic testing indicated the existence of both a dis-bond and a kiss-bond (see Figure 4). In order to ensure that any machining, grinding or polishing would not modify the defective regions, 30 x $20 \mathrm{~mm}$ areas surrounding each defect were first cut away from the panel. These were mounted vertically in resin and then carefully milled back from the base until the defects were visible in the specimen cross-sections.

A repetitive procedure of grinding, polishing and microscopic imaging was undertaken to record the defect evolution through the length of each specimen. Polishing was conducted on a Buehler Alpha Vector machine using a range of abrasive papers from 80-2500 grit for the best microscopy results. Further use of $6 \mu \mathrm{m}, 3 \mu \mathrm{m}$ and $1 \mu \mathrm{m}$ polishing solutions on a manual Struers Knuth Rotor machine were found to improve the optical clarity of the specimen cross-sections; however, this process also appeared to hide fine, crack-like, features in the defect region that had been clearly visible after polishing with 2500 grit abrasive paper. The masking of these features was expected to be the result of fine debris filling and smoothing the similarly sized cracks.

An optical microscope was used to examine the defect specimen after each polishing phase, and a Hitachi FlexSEM-1000 Scanning Electron Microscope (SEM) was used to take high magnification images of the major features.

\subsection{SEM observations}

Optical microscopy showed that the middle pre-cured plies in each defect specimen were quite flat, with a 50-100 $\mu \mathrm{m}$ thick resin-rich region between them, as seen in Figure 11 and Figure 12. However, despite careful layup, the two adjacent precured areas were not perfectly aligned; reflected by a slight offset between these flat regions at the defect edges.

From the SEM images shown in Figure 11, a long, continuous and fine crack-like feature was observed in the $6 \mathrm{~mm}$ defect, at the interface between the pre-cured plies. This was expected to be a kiss-bond, with negligible volume, intimate contact and no bonding. As shown in SEM - B from Figure 11 (taken at 550x magnification), this defect was less than $5 \mu \mathrm{m}$ thick and was located on one side of the resin-rich interface. This kiss-bond was seen to extend for the full width of the pre-cured region, until finishing at a small lip in SEM - A of Figure 11, which was likely to be partially cured region of resin spew from the pre-curing process.

Alternatively, the $10 \times 10 \mathrm{~mm}$ defect revealed large and deep voids, as seen in Figure 12, which encased a significant amount of 'loose resin' that did not appear to be bonded to the pre-cured plies on either side of the interface. This loose 
resin was deemed to result from the pre-cure process, and not from the grinding process, due to its long, long, thick, deep and continuous nature. It therefore appears to be resin that has flowed into the void between pre-cured plies and has not bonded to the sides.

At high magnification, there were also signs of the interfaces between the pre-cured plies and the rest of the cured laminate, shown in SEM - C from Figure 12. However, these did not extend for the full length of the $10 \mathrm{~mm}$ defect.

\subsection{Defect evolution}

In total, a series of nine slices were inspected over a length of around $2.1 \mathrm{~mm}$ in each of the two specimens, representing $20 \%$ and $35 \%$ of the full $10 \times 10 \mathrm{~mm}$ and $6 \times 6 \mathrm{~mm}$ defect lengths respectively. After each grinding/polishing iteration, digital Vernier callipers were used to measure the specimen thickness change, in order to determine effective distance between each cross-section. Figure 13 shows these relative distances for each slice in relation to the first cross-section, for each defect. Due to the difficulty of locating these defects within the laminate, it was not possible to know the exact position of the first cross-section relative to each defect. However, the estimated location is shown in Figure 13.

Similarly-sized sub-sections from each slice were used to assess the void content in the defective areas. These sub-sections covered the full pre-cured defect regions from the two middle plies of the laminate, as shown in Figure 14 and Figure 16, for the $6 \times 6 \mathrm{~mm}$ and $10 \times 10 \mathrm{~mm}$ defect specimen respectively. Outside of these areas, no other detectable voids were observed, suggesting that the voids resulted from the pre-curing and re-curing process.

Under the optical microscope at 20x magnification, the visible voids $(>5 \mu \mathrm{m})$ in each slice sub-section were evaluated. The 6 x $6 \mathrm{~mm}$ defect specimen showed a few, relatively small, voids that were mostly evident in the middle of a pre-cured ply; rather than at the interface between the two pre-cured plies. Figure 14 shows the sub-section region from the $1.0 \mathrm{~mm}$ slice of the 6 × $6 \mathrm{~mm}$ defect, highlighting two voids: an air bubble within the resin between tows, and a dry spot within the tow fibres. In relation to Non-Destructive Inspection, such small voids are expected to be at the limits of detection for typical phased-array ultrasonic transducers that have a maximum resolution of 0.8-1.0 $\mathrm{mm}$. The very small voids from each similar slice sub-section in the $6 \times 6 \mathrm{~mm}$ defect specimen are displayed in Figure 15.

In the $10 \times 10 \mathrm{~mm}$ defect specimen, much larger voids were observed in the pre-cured ply interface, along with a considerable region of 'loose resin' that was not well attached to either pre-cured ply. Figure 16 highlights these defects in the $0.9 \mathrm{~mm}$ slice, where some small pockets of dry areas were also seen in the transverse fibres of the pre-cured plies. The scale and highly-connected nature of these larger voids can be seen in Figure 17 for each of the nine microscopy subsections in the $10 \times 10 \mathrm{~mm}$ defect specimen. The same large void in the pre-cured ply interface was observed through all slices, with a thickness of 60-100 $\mu \mathrm{m}$. This explains the greater signal response from ultrasonic NDI in this area, as such a large defect would result in considerable attenuation. Subsequently, the average void area among the nine slices of the $10 \times 10 \mathrm{~mm}$ defect specimen was found to be more than twenty times that of the $6 \times 6 \mathrm{~mm}$ defect specimen.

\section{Discussion}

The proposed method to manufacture kiss-bonds has the potential to improve knowledge of NDI system capabilities, leading to improved confidence in inspection methods. Likewise, characterisation data on the residual strength of specimens can be used to improve design allowables. To this end, the method is discussed in terms of its reliability, capabilities, and areas for further development. The performance of the ultrasound and laser shearography NDI methods used will be discussed. 


\subsection{Technique developed}

In this study, ten defects were manufactured. All were detected, with seven being identified as kiss-bonds using NDI. The remaining three were identified as dis-bonds due to the presence of voids. This is despite the fact that very small defect sizes were used (meaning that the accurate positioning of the pre-cured plies was critical). This shows promise in the method's ability to produce kiss-bonds reliably, at defect sizes relevant to the aerospace industry, for example.

Nonetheless, there is room to improve the method further, and as such a number of observations and improvements are suggested. Firstly, the surface of the defect may be an influencing factor. The surface finish of the pre-cured areas was exceptionally flat and smooth. The use of vacuum bagging gives excellent surface quality in the pre-cured areas. However, the combination of resin-flow along with the pressure applied by the vacuum bagging results in the pre-cured area being compacted when compared to the rest of the ply. This results in a concave section over the defect area. When two plies are stacked adjacently, these concave sections may not sit precisely into each other, giving rise to a cavity - and thus a disbond - being formed.

The method of using an air cavity to thermally isolate the tool-plate directly under the pre-cure area from the rest of the tool plate has resulted in excellent temperature control. This process results in a resin-rich 'ridge' being formed along the border of the defect (see Figure 11, SEM - A). This ridge can lead to the formation of a dis-bond, where the defect surfaces are not in intimate contact. To this end, it may be possible to use a material with a high thermal conductivity in the area under the defect, while using thermally insulating materials for the remainder of the tool-plate. Such a material type can eliminate the need for an air-cavity, resulting in a smooth and unbroken tool-plate surface.

Finally, the effect of defect depth may need to be considered with regards to the type of defect produced. The laminates used in this study were relatively thin ( 8 plies). Following cure of the laminate at elevated temperature, it is possible that thermally induced residual stresses (following the cool-down from cure to room temperatures) may cause distortion of the laminate above and below the defect. This may cause the defect to be forced open or closed, causing a dis-bond or a kissbond to be produced.

\subsection{NDI of kiss-bonds}

Both NDI methods were capable of detecting the defects produced (with a validated process when using ultrasonics). In this study, ultrasonics was able to discern between the two defect types, while the ability of laser shearography was not explored.

In the case of ultrasonics, it is clear that it offers significant promise in detecting and assessing the defect type. However, applying the correct settings (gates, gain, etc.) required a high level of care so as not to get misleading results. Using this approach requires care to ensure that the back-wall echo is not a repeat echo of the defect produced (especially when the defects are in the laminate mid-plane). To combat this, the defect could be inserted away from the mid-plane, so that the repeat echo would not coincide with the back-wall.

In the case of shearography, the excitation method used was relatively simple and gave good results. However, getting further information (e.g. the depth of the defect and the defect type) is more difficult using this technique. That said, shearography remains a very flexible technique, open to various excitation and post-processing options, and so techniques may exist to obtain further information.

\subsection{Opportunities}

The ability to consistently manufacture representative defects using this techniques introduces the possibility to perform a wide range of mechanical and NDI investigations, which previously have not been possible. Firstly, the effect of kiss- 
bonds on structural performance of a composite may be more accurately assessed. The flexibility of the technique, in terms of defect size, shape and location, allows for a comprehensive analysis on the effects of kiss-bonds, leading to a better understanding of damage growth mechanisms. Consequently, this can aid in the optimised design of damage tolerant structures. Results from any mechanical characterisation may also be utilised to validate finite element models of defect growth under loading.

As the method relies on local curing of a material, it can be applied to other materials/structural-configurations that are open to such manipulation, once the thermosetting nature can be utilised (i.e. not limited to biaxial pre-preg fabrics). For example, kiss-bonds could be inserted into the bond-line of a repair by pre-curing a section of the bonding-adhesive. In addition, an exciting opportunity exists to further develop this technique to create bonded areas with a degraded, yet controlled, bond strength (i.e. weak-bonds). By not entirely curing the material, it may be possible to introduce some degree of cure across the defect during the subsequent curing process. The curing time required to produce a certain degree of bonding (and thus mechanical strength) can be calibrated through DSC experiments (determining the degree of cure) and mechanical testing (determining the degraded mechanical performance). This offers enormous potential in terms of directly correlating NDI system capabilities against the degraded structural performance caused by a 'weak-bond'.

\section{Conclusions}

A simple and innovative method for directly manufacturing kiss-bonds defects in composite laminates has been developed. The method addresses many shortcomings of existing techniques that simulate defects using film inserts or by creating artificial voids, and as such, has applications for NDI equipment qualification and calibration, as well as more accurately characterising the residual strength of structures with defects. The method relies on using the thermosetting nature of a prepreg composite laminate, and can provide control over the defect size, shape and location.

A total of ten $6 \times 6 \mathrm{~mm}$ and $10 \times 10 \mathrm{~mm}$ defects were manufactured in flat, monolithic CFRP laminates, which were detectable using ultrasonic and shearography inspection techniques. Of these, seven defects were categorised by ultrasonic inspection as being kiss-bonds, with the remainder being dis-bonds. Optical and SEM microscopy of a kiss-bond and disbond defect showed that kiss-bonds featured very good areas of contact with only very small cavities present. Dis-bond defects featured larger and more frequent cavities. During preparation, the surface of the pre-cured plies showed a small lip of cured resin surrounding the defect area as well as a small 'concave' indentation. Combined with any misalignment of adjacent pre-cured plies, these features can lead to the dis-bonds identified. Addressing these factors can improve the reliability of the method developed.

The results of this study show significant promise towards a reliable defect manufacturing method. In addition to NDI system assessment and calibration, the produced defects can be used to characterise the residual strength of components with kiss-bonds. In addition, the technique can be altered to produce weak-bonds (i.e. defects with some degree of bonding across the plane of the defect).

\section{Acknowledgments}

The authors Telford, O'Carroll and Young would like to acknowledge Enterprise Ireland and IDA Ireland for research funding through the IComp (Irish Composites Centre) REPCOMP project. The author Pierce would like to acknowledge funding support from the Northern Ireland Advanced Engineering Competence Centre (NIAECC). The authors acknowledge and thank Bombardier Aerospace, Belfast for their significant technical input, which included defining the problem, providing thermal analysis methods and analysing the output, generating the ultrasonic procedure and supplying material to facilitate the manufacture of the test panels. 


\section{References}

1. Yang, S., L. Gu, and R.F. Gibson, Nondestructive detection of weak joints in adhesively bonded composite structures. Composite Structures, 2001. 51(1): p. 63-71.

2. Katnam, K.B., L.F.M. Da Silva, and T.M. Young, Bonded repair of composite aircraft structures: A review of scientific challenges and opportunities. Progress in Aerospace Sciences, 2013. 61: p. 26-42.

3. Paska, J., M. Sałek, and T. Surma, Current status and perspectives of renewable energy sources in Poland, Renewable and Sustainable Energy Reviews, 2009. 13(1): p. 142-154.

4. Roach, D., Neidigk, S., Rice, T., Duvall, R. and Paquette, J., Blade Reliability Collaborative: Development and Evaluation of Nondestructive Inspection Methods for Wind Turbine Blades, Sandia National Labs, Sandia Report SAND2014-16965, 2014.

5. Poveromo, S.L. and J.C. Earthman, Development of Percussion Diagnostics in Evaluating 'Kiss' Bonds Between Composite Laminates, in Advanced Composites for Aerospace, Marine, and Land Applications. 2014, Springer. p. 213-229.

6. Barnes, T.A. and I.R. Pashby, Joining techniques for aluminium spaceframes used in automobiles: Part II adhesive bonding and mechanical fasteners. Journal of Materials Processing Technology, 2000. 99(1): p. 72-79.

7. Brotherhood, C.J., Drinkwater, B.W., and S. Dixon, The detectability of kissing bonds in adhesive joints using ultrasonic techniques. Ultrasonics, 2003. 41(7): p. 521-529.

8. Nagy, P.B., Ultrasonic detection of kissing bonds at adhesive interfaces. Journal of Adhesion Science and Technology, 1991. 5(8): p. 619-630.

9. Wood, M., P. Charlton, and D. Yan, Ultrasonic evaluation of artificial kissing bonds in CFRP composites. The eJournal of NDT, 2014. 19(12).

10. FAA Advisory Circular, "AC20-107B - Composite Aircraft Structure”, U.S. Depatrment of Transportation, Federal Aviation Administration, 2009.

11. Bossi, R., Housen, K.R, Walters, C.T. and Sokol, D., Laser bond testing, Materials Evaluation, 2009. 67(7): p. 819-827.

12. Marty, P.N., N. Desai, and J. Andersson. NDT of kissing bond in aeronautical structures, in 16th World Conference on NDT. 2004.

13. Chen, B., Soh, S., Lee, H., Tay, T. and Tan, V., A vibro-acoustic modulation method for the detection of delamination and kissing bond in composites. Journal of Composite Materials, 2016. 50(22): p. 3089-3104.

14. Vijaya Kumar, R.L., M.R. Bhat, and C.R.L. Murthy, Evaluation of kissing bond in composite adhesive lap joints using digital image correlation: Preliminary studies, International Journal of Adhesion and Adhesives, 2013. 42: p. 60-68.

15. Gower M., Lodeiro M., Aktas A., Shaw R., Maierhofer C., Krankenhagen R., Augustin S., Rollig M., Knazovicka L., Blahut A., Monte C., Judaschke R. and Ségur D, Design and manufacture of reference and natural defect artefacts for the evaluation of NDE techniques for fibre reinforced plastic (FRP) composites in energy applications. in Proceedings of 19th World Conference on Non-destructive Testing, Munich, 2016.

16. Roach, D., Rackow, K. and Duvall, R., Innovative use of adhesive interface characteristics to nondestructively quantify the strength of bonded joints. in 10th European Conference on Non-Destructive Testing. 2010.

17. Hung, Y.Y., Applications of digital shearography for testing of composite structures. Composites Part B: Engineering, 1999. 30(7): p. 765-773.

18. Kundu, T., Maji, A., Ghosh, T. and Maslov, K., Detection of kissing bonds by Lamb waves, Ultrasonics, 1998. 35(8): p. 573-580.

19. Yan, D., Drinkwater, B.W. and Neild, S.A., Measurement of the ultrasonic nonlinearity of kissing bonds in adhesive joints. NDT \& E International, 2009. 42(5): p. 459-466.

20. Adams, D.E., Sharp, N.D., Myrent, N. and Sterkenburg, R., Inspection for kissing bonds in composite materials using vibration measurements. in Nondestructive Characterization for Composite Materials, Aerospace Engineering, Civil Infrastructure, and Homeland Security, 2011.

21. Telford, R., O'Carroll, A. and Young T.M., Creating kiss-bonds for non-destructive inspection in $21^{s t}$ International Conference on Composite Materials, Xi'an, China, August 2017.

22. Nagy P.B. Ultrasonic classification of imperfect interfaces, Journal of Nondestrutive Evaluation 1992;11:127-39.

23. Brotherhood C.J., Drinkwater B.W. and Guild F.J. The effects of compressive loading on the detectability of kissing bonds in adhesive joints, Journal of Nondestrutive Evaluation

2002;21(3):95-104.24. Jeenjitkaew C., Luklinska Z., and Guild F., Morphology and surface chemistry of kissing bonds in adhesive joints produced by surface contamination, International Journal of Adhesion and Adhesives., 30 (7), 2010, p.643-653.

25. Nagy P.B., Ultrasonic classification of imperfect interfaces, Journal of Adhesive Science Technology 5 (8) (1991) 619-630

26. Jeenjitkaew C. and Guild F.J., The analysis of kissing bonds in adhesive joints, International Journal of Adhesion and Adhesives., 2017 (75) 101-107 
27. Heide-Jorhense, S., Budzik, M.K., Effects of bondline discontinuity during growth of interface cracks including stability and kinetic considerations, Journal of the Mechanics and Physics of Solids, 2018 (117) 1-21

28. Heide-Jørgensen S.,Teixeira de Freitas S., Budzik M.K., On the fracture behaviour of CFRP bonded joints under mode I loading: Effect of supporting carrier and interface contamination, Composites Science and Technology, 2018, (160) 97-110. 


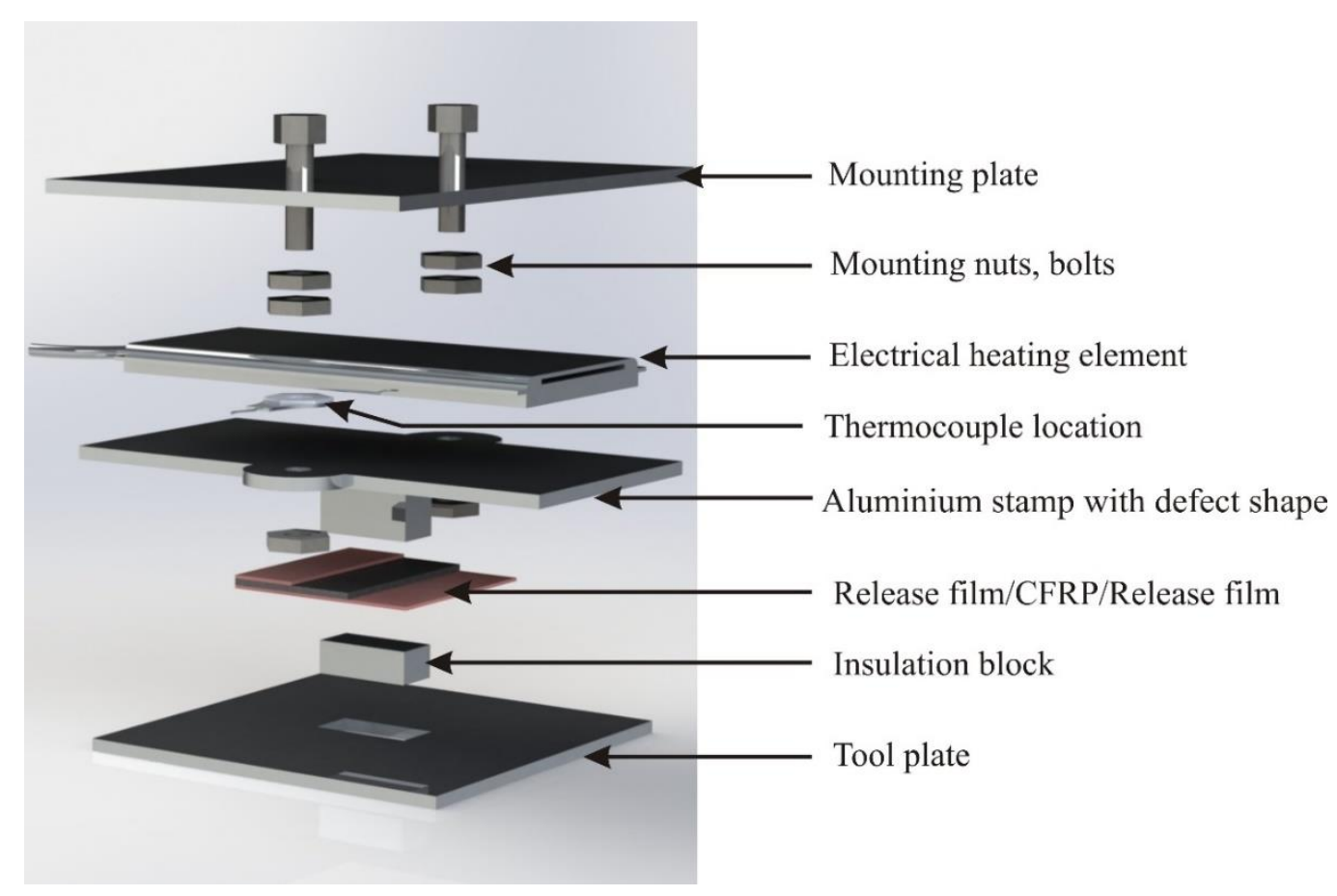

Figure 1 - Exploded view of equipment used to pre-cure areas of individual plies 


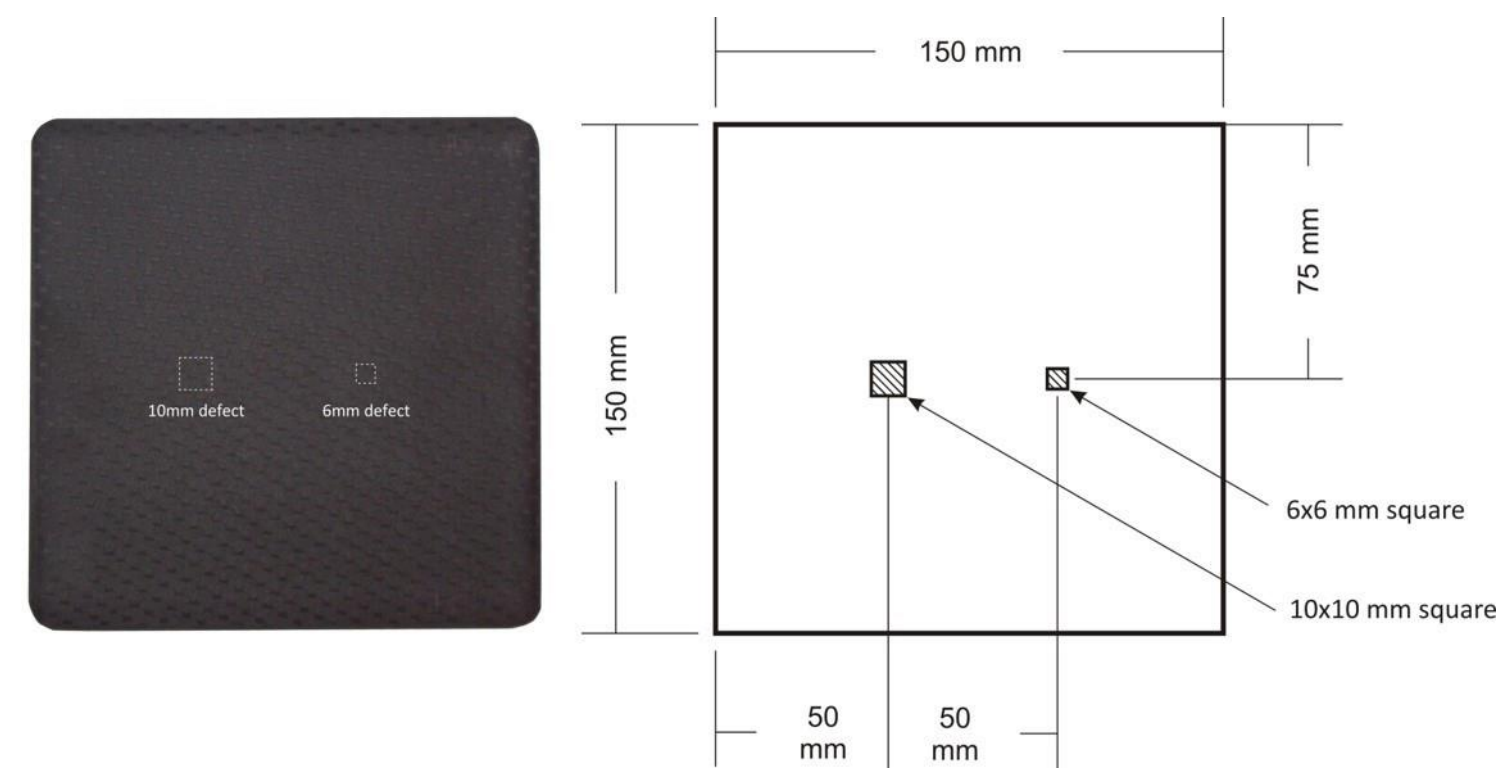

Figure 2 - Dimensions of the panels produced, showing the kiss-bond area locations

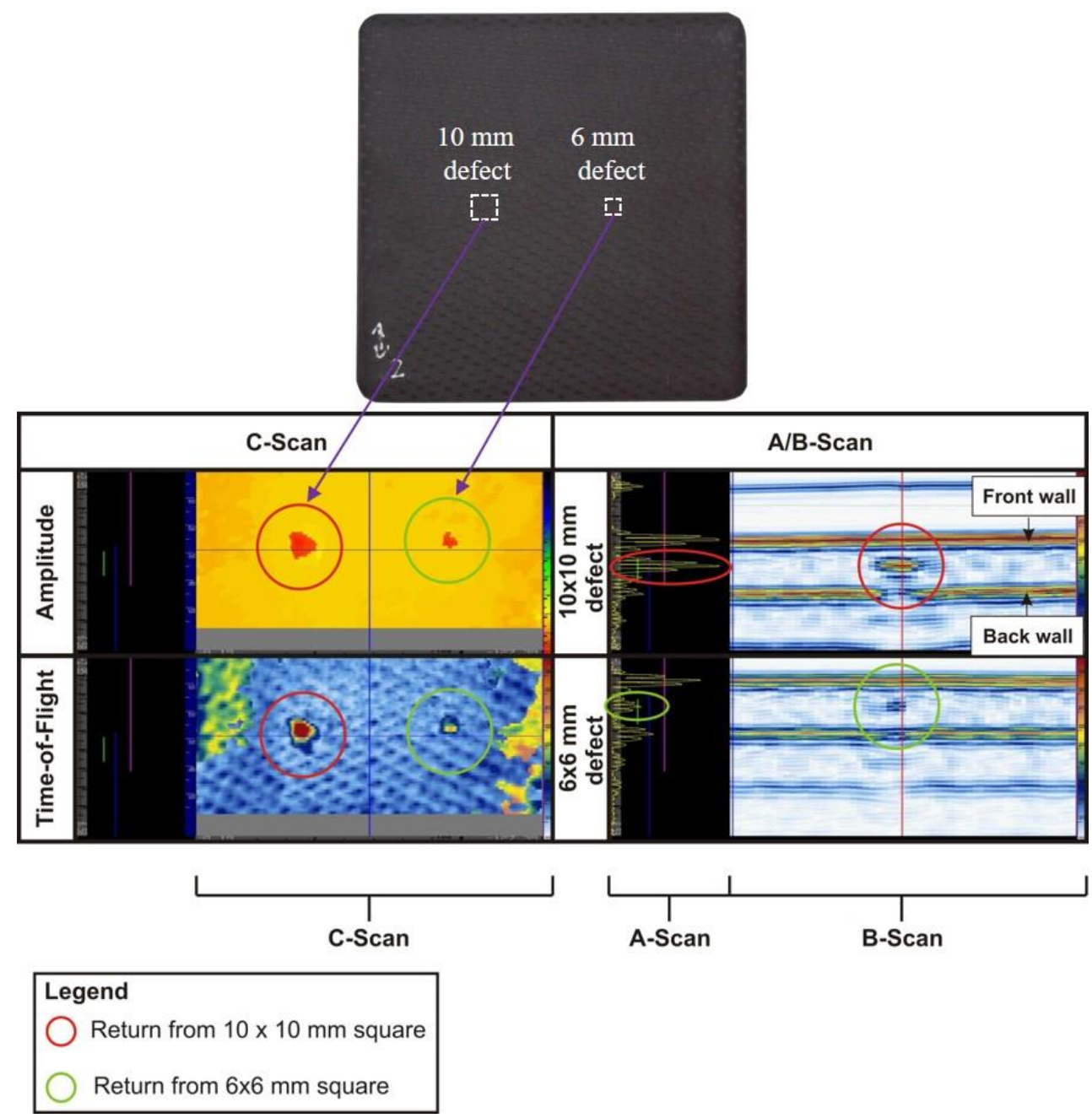

Figure 3 - Ultrasonic investigation of panel 1 


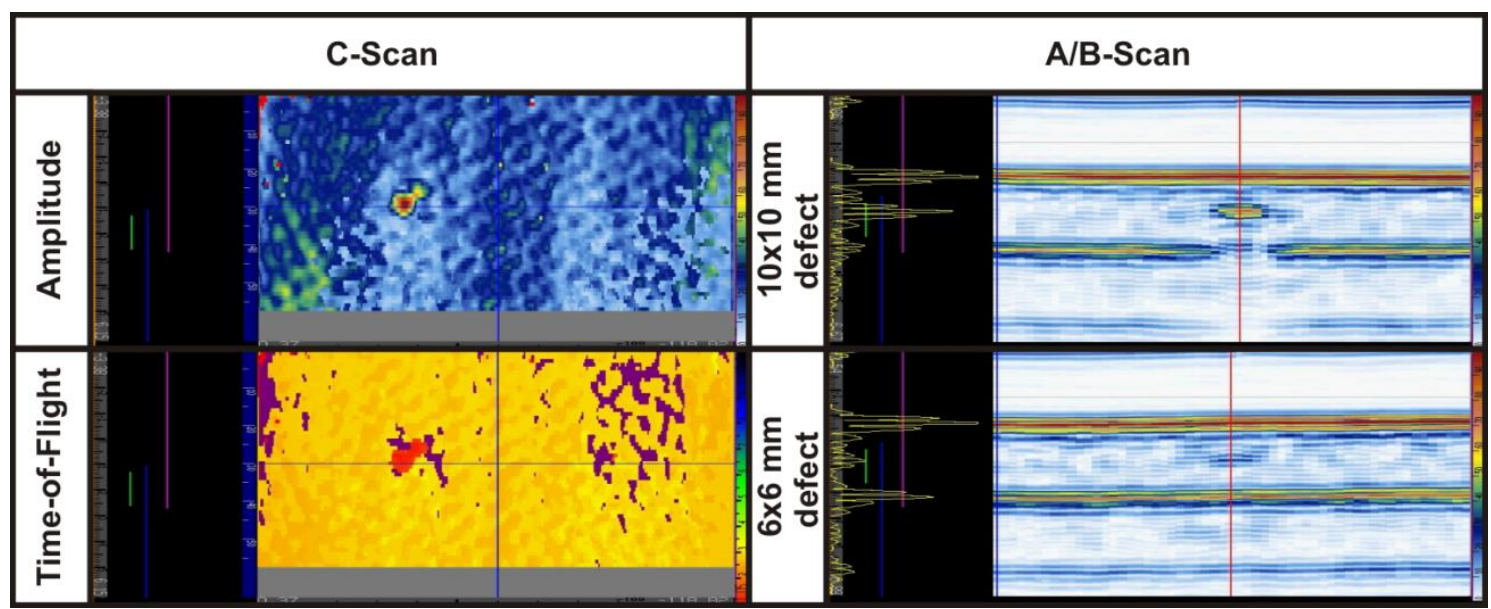

Figure 4 - Ultrasonic investigation of panel 2

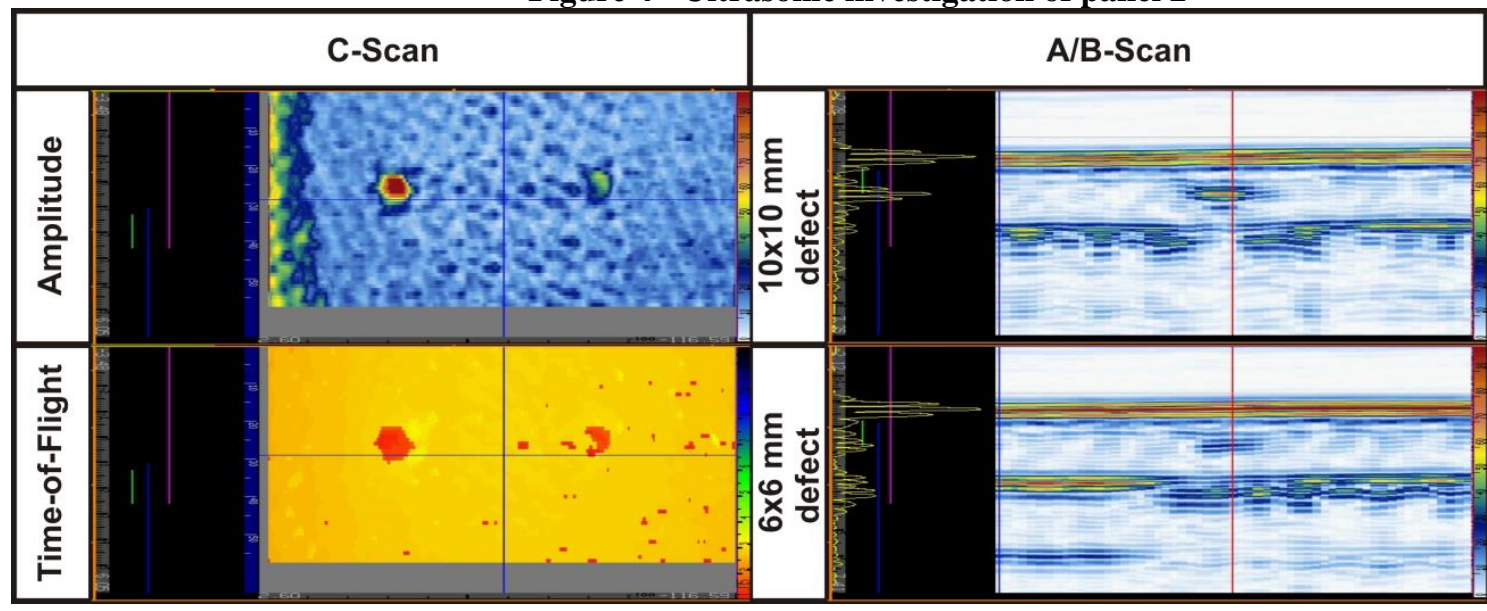

Figure 5 - Ultrasonic investigation of panel 3

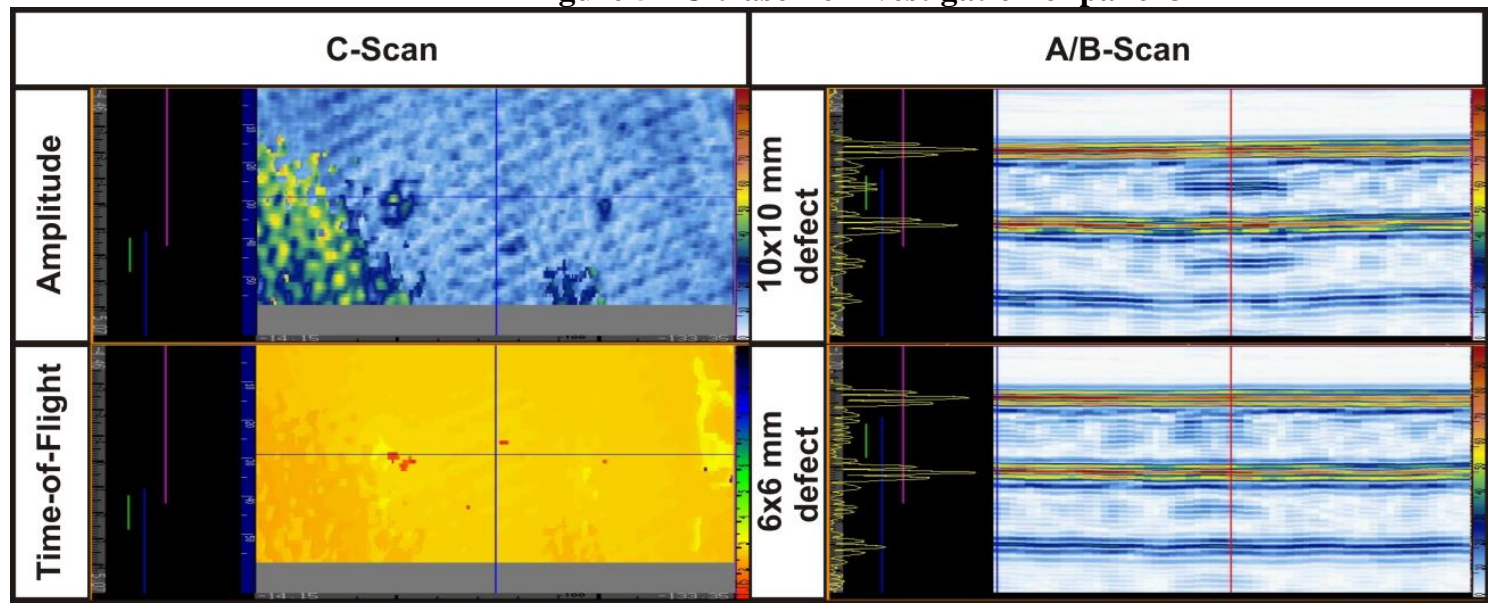

Figure 6 - Ultrasonic investigation of panel 4 


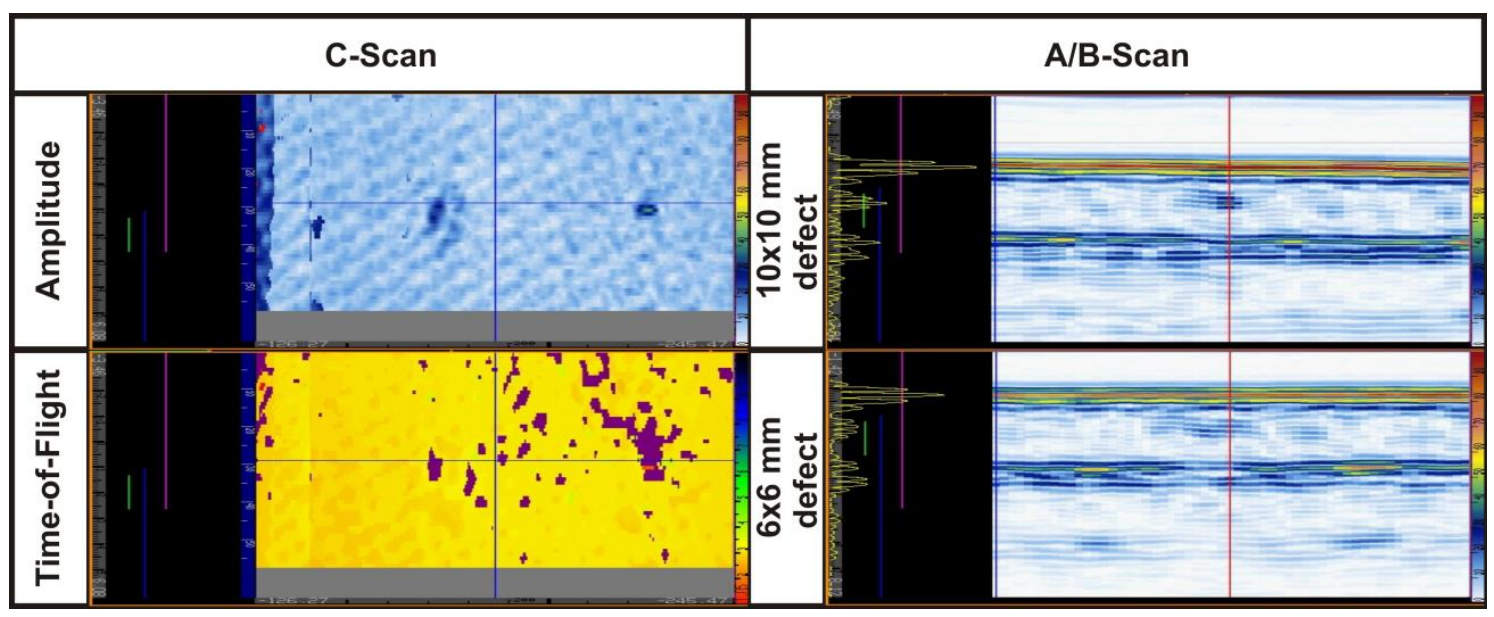

Figure 7 - Ultrasonics investigation of panel 5

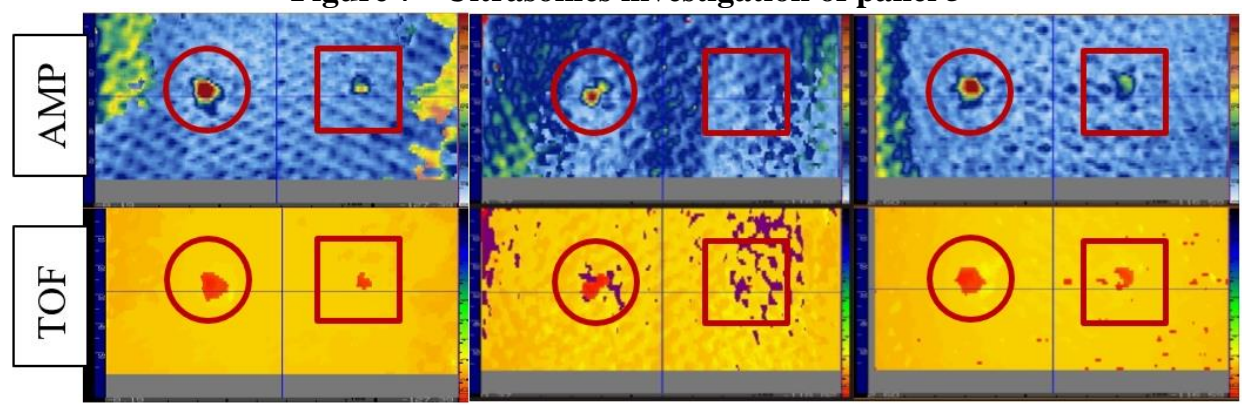

Panel 1

Panel 2

Panel 3

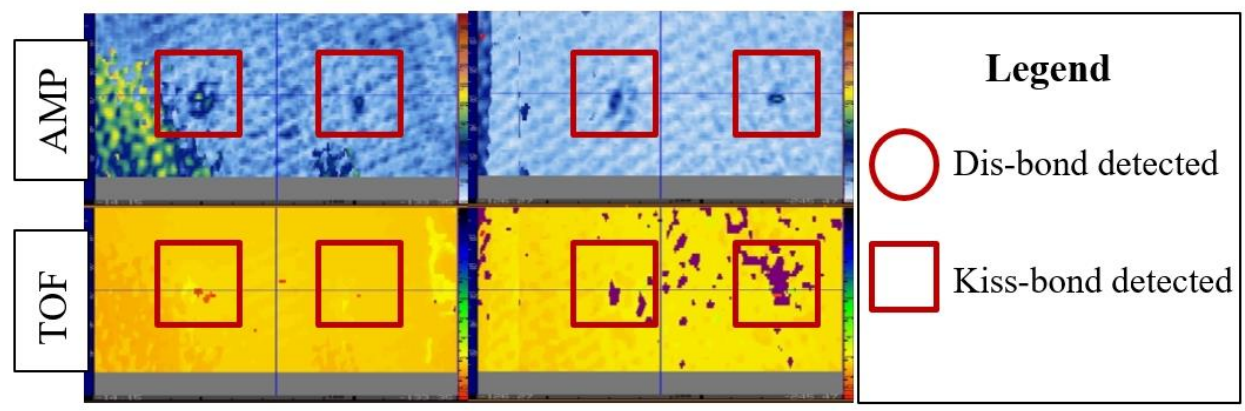

Panel 4

Panel 5

Figure 8 - Summary of ultrasonic investigation results

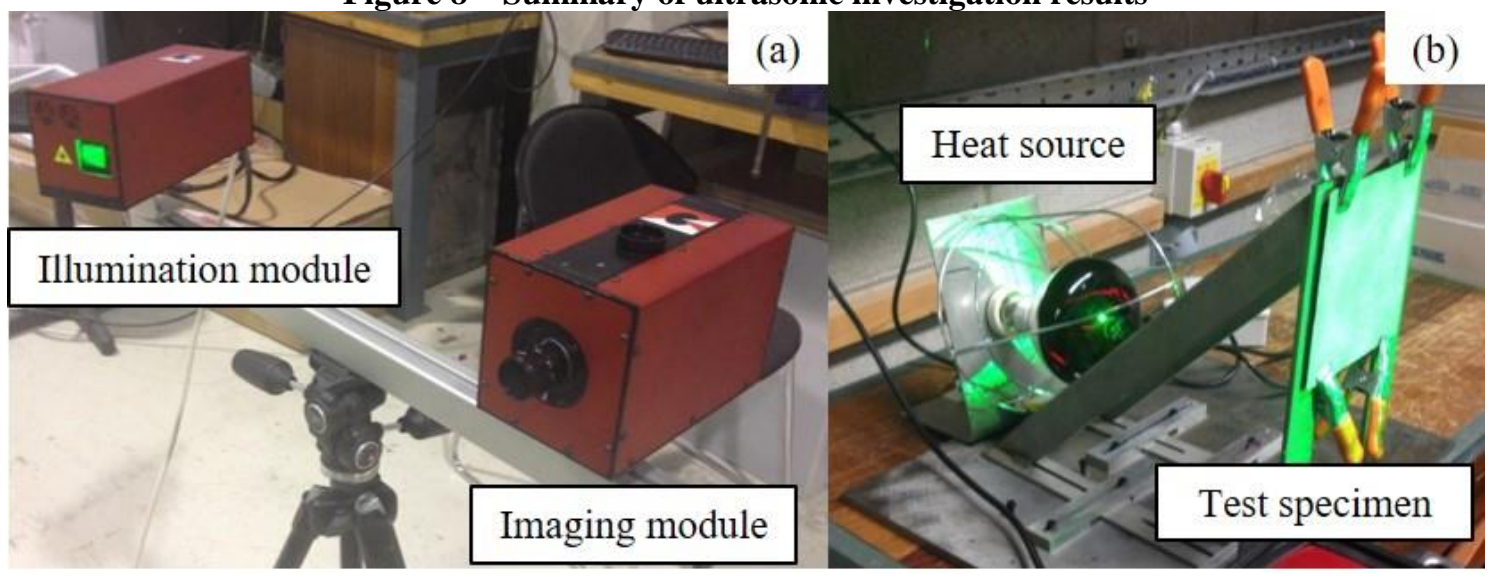

Figure 9 - (a) Laser shearography NDI system and (b) test specimen and clamp used 


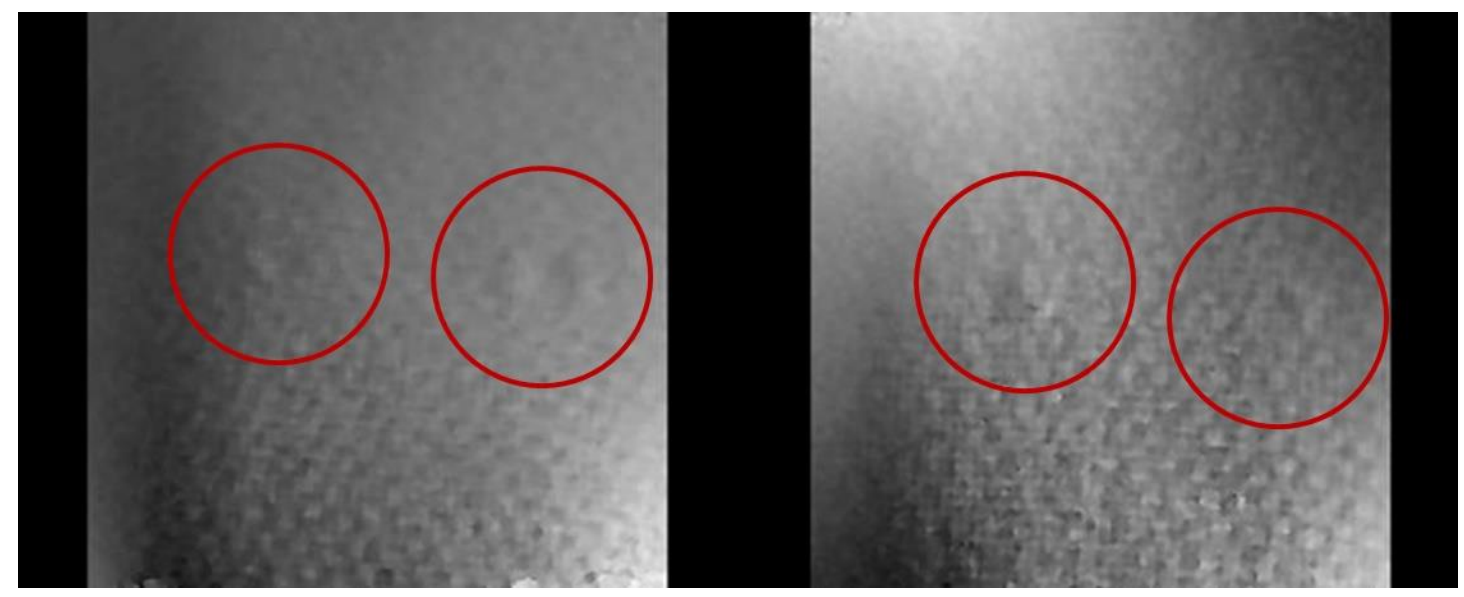

Figure 10 - Laser shearography image, with location of detected defects
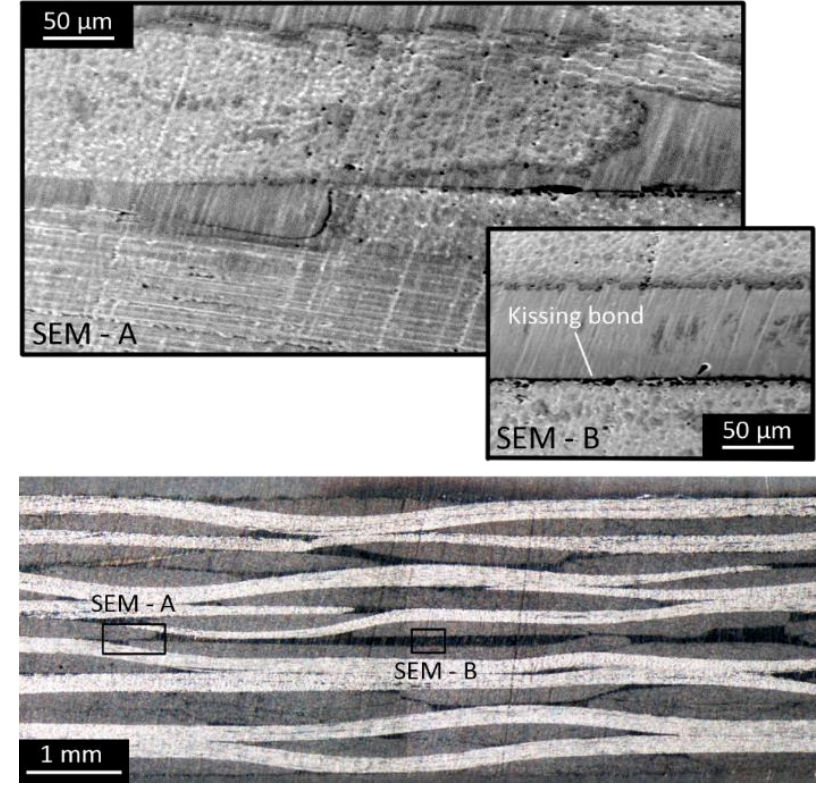

Figure 11 Cross-section of the 6 × $6 \mathrm{~mm}$ defect specimen, including SEM images from the edge (SEM - A) and middle (SEM - B) of the defect area.
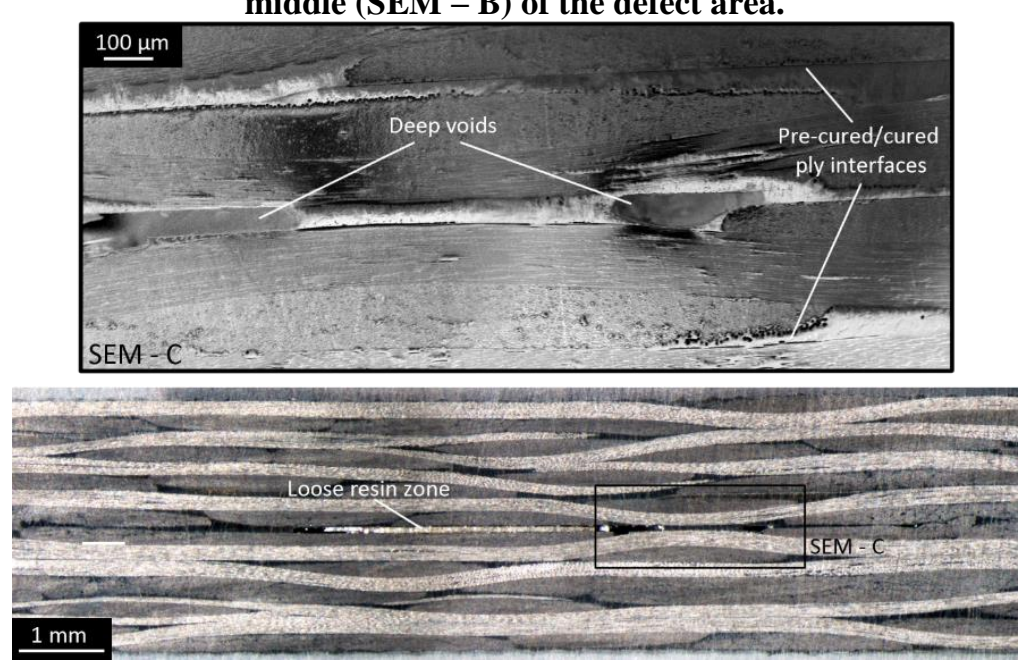

Figure 12 Cross-section of the 10 x $10 \mathrm{~mm}$ defect specimen, with feature close-up (SEM - C). 


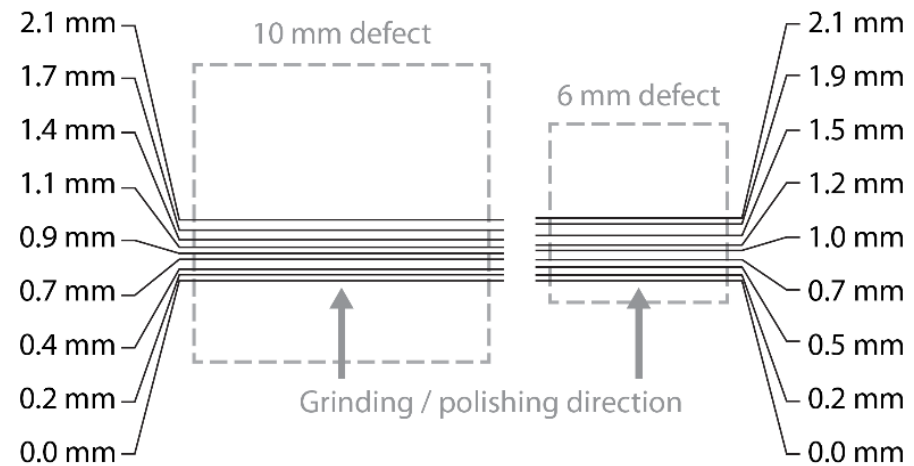

Figure 13 Relative location of each cross-section for both microscopy specimens.

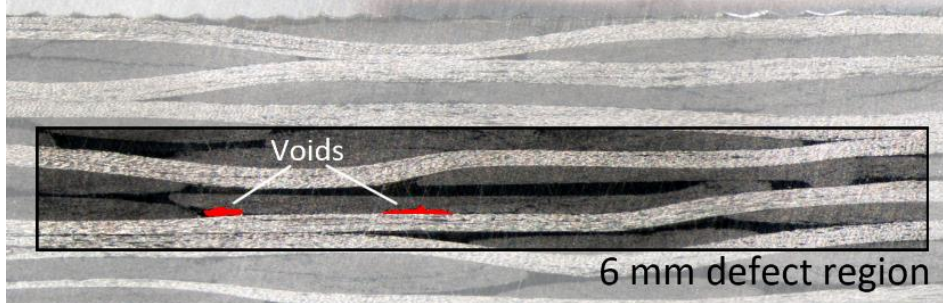

$1 \mathrm{~mm}$

Figure 14 Sub-section from the $1.0 \mathrm{~mm}$ slice of the $6 \times 6 \mathrm{~mm}$ defect specimen

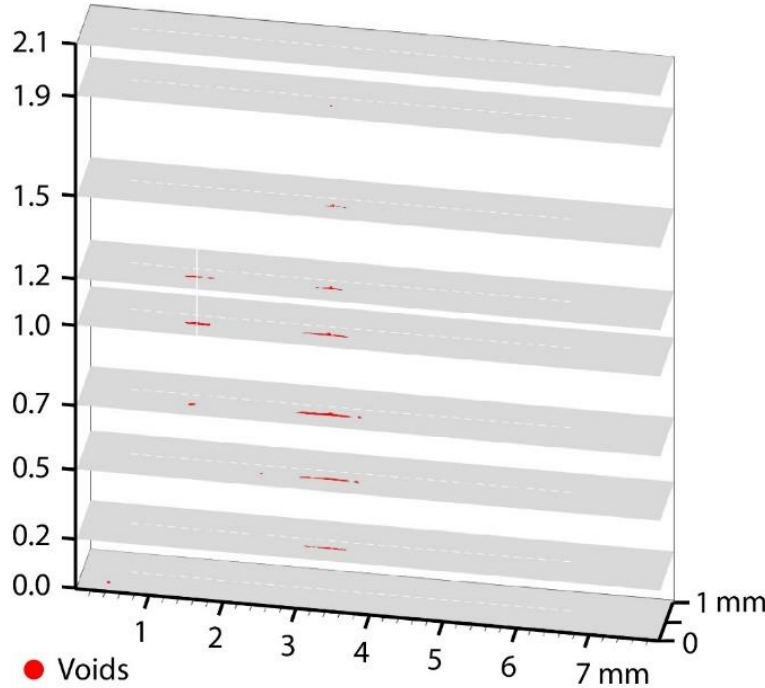

Figure 15 Void content in the sub-sections of each slice for the $6 \times 6 \mathrm{~mm}$ defect specimen.

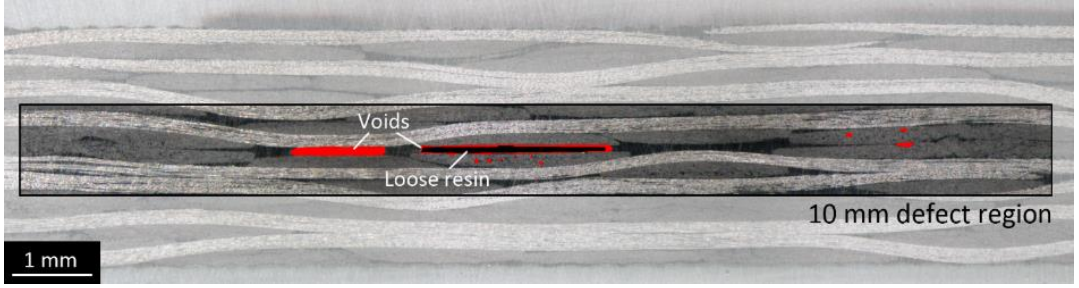

Figure 16 Sub-section from the $0.9 \mathrm{~mm}$ slice of the $10 \times 10 \mathrm{~mm}$ defect specimen. 


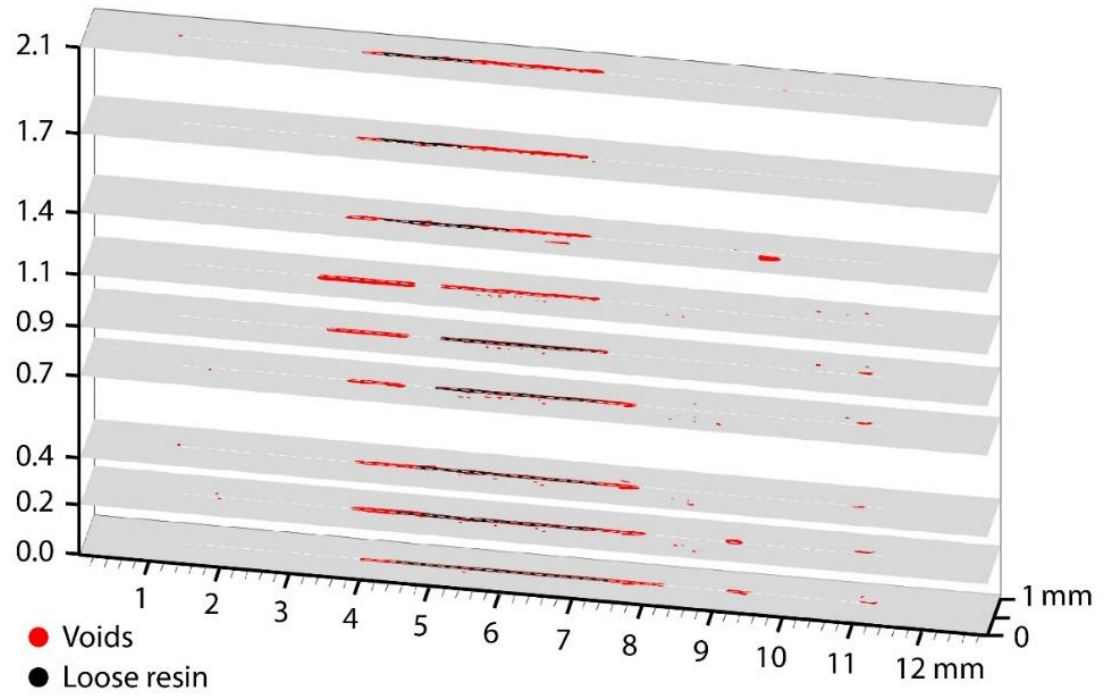

Figure 17 Void content in the sub-sections of each slice for the $10 \times 10 \mathrm{~mm}$ defect specimen.

Table 1 Operating principles of popular NDI systems

\begin{tabular}{|c|c|c|}
\hline System & Operating principle & Defect characteristic detected \\
\hline Ultrasonics & $\begin{array}{l}\text { Monitoring reflection of sound waves } \\
\text { travelling through the thickness of a } \\
\text { component }\end{array}$ & $\begin{array}{l}\text { Surface-interface created by the } \\
\text { defect }\end{array}$ \\
\hline $\begin{array}{l}\text { Laser } \\
\text { shearography }\end{array}$ & $\begin{array}{l}\text { Monitoring local alterations to surface strains } \\
\text { following mechanical loading }\end{array}$ & $\begin{array}{l}\text { Change in local stiffness caused by } \\
\text { the defect }\end{array}$ \\
\hline Thermography & $\begin{array}{l}\text { Monitoring surface temperature gradients } \\
\text { during a temperature change }\end{array}$ & $\begin{array}{l}\text { Local change in thermal } \\
\text { conductivity caused by defect }\end{array}$ \\
\hline Radiography & Monitoring X-rays absorbed by component & Change in density at the defect \\
\hline $\begin{array}{l}\text { Laser bond } \\
\text { inspection* }\end{array}$ & $\begin{array}{l}\text { Uses laser to assess, test and re-assess bond } \\
\text { interfaces }\end{array}$ & Strength reduction due to defect \\
\hline $\begin{array}{l}\text { Vibro-acoustic } \\
\text { modulation }\end{array}$ & $\begin{array}{l}\text { Vibrating the structure to open and close any } \\
\text { cracks that exist }\end{array}$ & $\begin{array}{l}\text { Change in vibrational response } \\
\text { due to defect }\end{array}$ \\
\hline
\end{tabular}

*This technique is included for completeness, but may damage the structure if an inadequate bond is present and are thus not strictly non-destructive in nature. 